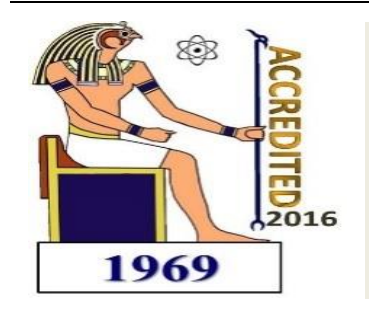

Delta Journal of Science

Available online at

https://djs.journals.ekb.eg/

Research Article

MICROBIOLOGY

\title{
THE ROLE OF EXOPOLYSACCHARIDE PRODUCED BY Pleurotus Sapidus AS MEDICAL AGENT
}

\author{
Eman H. F. Abd El-Zaher*1, Alaa M. Abou Zied ${ }^{1}$, Youssef M. Mohamed ${ }^{2}$, Faten M. A. Semana ${ }^{1}$ \\ 1 Botany and Microbiology Department, Faculty of Science, Tanta University, Tanta, Egypt., \\ 2 Botany and Microbiology Department, Faculty of Science, Damanhour University, Damanhour, Egypt. \\ * Correspondence author: Eman H.F. Abd El-Zaher E-mail: eimanabdelzaher @ yahoo.com
}

\section{KEY WORDS}

Exopolysaccharides,

production, Box

Benken, factorial

design, biological

activity, Pleurotus

sapidus

\section{ABSTRACT}

Mushrooms have been used since centuries for the treatment of different diseases and efforts were made to isolate different compounds from the mushrooms responsible for medicinal activities. Among the mushroom genus Pleurotus is worldwide in distribution due to their medicinal properties such interventions ameliorate hepatic lipid profiles, reduce inflammation and oxidative stress, noticeable antioxidant, antiinflammatory, antimicrobial, antitumor and analgesic properties. These properties are attributed mainly to polysaccharides synthesized by Pleurotus. The aim of current study is to improve of Exopolysaccharide production by Pleurotus sapidus through manipulation of different culture and environmental conditions using response surface methodology (RSM). Plackett-Burman design indicated that; shaking, starch and incubation temperature are the most effective parameters. Box-Behnken RSM indicated that; the optimum concentration for each parameter was: 148.9 $\mathrm{rpm}$ for shaking, 30.1g/l starch and $25.2{ }^{\circ} \mathrm{C}$ for incubation temperature. After production, EPS was extracted, purified, identified using Fourier transform infrared (FTIR), Nuclear Magnetic Resonance ( $\left.{ }^{1} \mathrm{HNMR}\right)$ and High Performance Liquid Chromatography (HPLC). The result indicated that; it consisting of $\beta-(1 \rightarrow 3)$ glucans, $\beta-(1 \rightarrow 6)$ glucans branched, Chitin, Mannans and Galactans with different concentrations in EPS. Exopolysaccharides extracted from Pleurotus sapidus showed antitumor, antiviral, antibacterial, anticoagulant and antioxidant activity. 


\section{Introduction}

Microorganisms regularly preserve polysaccharides as a functional adaptation to prevent them from drying out and to help them adhere to surfaces (Hussien, 2019). Edible mushrooms have become attractive as "health foods" and as source materials for immunomodulators (Chen et al., 2018). They have beneficial effects such interventions ameliorate oxidative stress, hepatic lipid profiles, and reduce inflammation (Fontes $\boldsymbol{e t}$ al., 2019).

Several mushrooms belonging to Pleurotus species are confirmed to be producer of bioactive polysaccharide. It is one of most extensively studied white-rot fungi due to its exceptional ligninolytic properties (Hao et al., 2017\& Bellettini et al., 2016). Pleurotus, Flammulina, Ganoderma, Grifola, Trametes, Lentinus, Auricularia, Hericium, Schizophyllum, Tremella and Phellinus species are considered to be medically important mushrooms with essential bioactive properties (Deveci et al., 2019).

The main polysaccharides present in mushrooms are $\beta$-glucans with potential biological activities. $\beta$-glucans are soluble fibers and have physiological functions. One of this functions Is interference with absorption of sugars and reduction of serum lipid levels (Rahar et al., 2011). Mushroom polysaccharid- es such as $\beta-1,3$ glucan, $\beta-1,6$ glucan and lentinan have showed various health benefits i.e. anticancer, immunosuppressive hypertension, and diabetes (Bhakta and Kumar, 2013).

Mushrooms act as antibacterial and immune system enhancer; additionally, they are important sources of bioactive compounds. As a result of these properties, some mushroom extracts are used to promote human health (Valverde et al., 2018).
The genus Pleurotus contain many biological compunds such as polysaccharides, enzymes, protein, dietary fiber and vitamins (Shen $\boldsymbol{e t}$ al., 2013). It has been recently reported that many potential natural antioxidants are derived from lots of sources such as oilseeds, cereal crops, vegetables, fruits, leaves, roots, spices, herbs and mushrooms (Lee and Yoon, 2009).

Mushroom cultivation is reported as an economically viable bio-technology process for conversion of various lignocellulosic wastes. The mycelium growth of mushroom species is mainly dependents upon the substrate, nutrients and the growing conditions (Girmay et al., 2016). Compared with conventional methods, RSM can be used to design experiments, build models, search optimum factors for desirable responses, and evaluate the relative significance of several influence factors even in the presence of complex interactions. (Khuri et al., 2010). The purpose of the present research was to evaluate the growth factors that might increase the productivity of exopolysaccharides. Also, characterization of Exopolysaccharides using HPLC. Finally, antioxidant activity were analysed in vitro.

\section{Materials and methods}

\subsection{Producing organism and preservation}

Pleurotus sapidus species was obtained from mushroom and Mycology lab., department of plant pathology, Faculty of agriculture, Al-Azhar University, Cairo, Egypt. Pleurotus sapidus was preserved on sterilized slants containing Glucose yeast extract peptone media (GYP) which consisted of $\mathrm{gl}^{-1:}$ glucose 40 , yeast extract 10 , peptone 5, agar 15-20, chloroamphinicol 0.05 (as antibacterial agent), dissolved in $1 \mathrm{~L}$ of distilled water and autoclaved it at $121^{\circ} \mathrm{C}$ for 15 min . Prepared GYP slants were inoculated 
by the pure fungal cultures and incubated at $28{ }^{\circ} \mathrm{C}$. Slant cultures were transferred every month.

\subsection{Determination of Pleurotus sapidus dry weight}

Pleurotus sapidus was cultured in autoclaved $250 \mathrm{ml}$ flasks each was containing $100 \mathrm{ml}$ of Glucose yeast extract peptone media medium and incubated at $25^{\circ} \mathrm{C}$ for 7 days. After incubation the fungal biomass was separated by filtration and washed several times with sterile distilled water then dried at $80^{\circ} \mathrm{C}$ until a constant weight (Nour EL-Dein $\boldsymbol{e t}$ al ., 2004).

\subsection{Determination of EPS production}

Fungal culture filtrates were treated with 5\% Tri- choloroacetic acid (TCA) and left overnight to precipitate protein. The supernatant was mixed with two volumes of $95 \%(\mathrm{v} / \mathrm{v})$ of ethanol, stirred vigorously overnight at $4{ }^{\circ} \mathrm{C}$. The resultant precipitate was recovered by centrifugation (Hettich EBA 12R, Germany) at $3000 \mathrm{rpm}$ for 20 minutes (Wu et al., 2008). This step was repeated twice to remove impurities of low molecular weight compounds. Exopolysaccharide and carbohydrate contents were dissolved in deionized water and quantified using phenolsulfuric acid colorimetric method. All experiment was repeated in triplicate to calculate mean value of results (Dubios $\boldsymbol{e t}$ al., 1956). Crude exopolysaccharides were dialyzed with dialysis membrane to get ride of salts (Berg et al., 2007).

\subsection{Effect of different physiological parameters on mycelial growth and exopolysaccharides production of Pleurotus sapidus}

Different experiments were made to select the most favorable conditions for high production of exopolysaccharides dry weight.

\subsection{Effect of different media on mycelial growth and exopolysaccharides production of Pleurotus sapidus}

Four different liquid media; Potato dextrose broth (PDB) (Modified) It composed of $\mathrm{gl}^{-1}$; suspension / solution of potato extract 20 , dextrose 20 , dissolved in $1 \mathrm{~L}$ of distilled water and autoclaved it at $121{ }^{\circ} \mathrm{C}$ for $15 \mathrm{~min}$., Glucose yeast extract peptone media (GYP) It composed of $\mathrm{gl}^{-1}$; glucose 40 , yeast extract 10 , peptone 5 , dissolved in $1 \mathrm{~L}$ of distilled water and autoclaved it as described earlier., Malt extract Agar (MEA) It composed of $\mathrm{gl}^{-1}$; malt extract 20, dextrose 20 and dissolved in $1 \mathrm{~L}$ of distilled water and mushroom complete media ( $\mathrm{MCM}$ ) It composed of $\mathrm{gl}^{-1}$; glucose 20, peptone 2, yeast extract 2, $\mathrm{K}_{2} \mathrm{HPO}_{4} \quad 1$, $\mathrm{MgSO}_{4} 0.5$ and dissolved in $1 \mathrm{~L}$ of distilled water were used. Inoculate each medium with one fungal disc (with diameter size $0.7 \mathrm{~cm}$ ) of Pleurotus sapidus. After incubation for 7 days at $25^{\circ} \mathrm{C}$, the mycelial dry weight and exopolysaccharides were determined (Nour EL-Dein et al., 2004).

\subsection{Optimization of EPS using Plakett- Burman (PB) design}

The Plakett-Burman experimental design was applied to screen the significant variables that influence EPS production (Chen et al., 2011). Fourteen variables of medium composition and culture conditions were tested at low $(-1)$ and high $(+1)$ levels as shown in Table1. Based on PB matrix design, two-level factorial design, it allows the investigation of 14 variables $(n+1)$ (Plackett and Burman, 1946). On this design all trials were performed in triplicate and the averages of EPS production were treated as the responses. The main effect of each variable was determined with the following equation:

$$
E_{x i}=\left(\Sigma M_{i+}-\Sigma M_{i-}\right) / N
$$


Where $E_{x i}$ is the variable main effect, $M_{i+}$ and $\mathrm{M}_{\mathrm{i}-}$ are EPS production in trials where the independent variable (xi) was present in high and in low settings, respectively, and $\mathrm{N}$ is the number of trials divided by 2. For determination of variable significance, statistical t-values for equal unpaired samples were calculated with respect to observations. The variables significant at $95 \%$ level $(\mathrm{p}<0.05)$ were considered to have significant effect on EPS production and thus used for further optimization.

\subsection{Response surface methodology}

Box-Behnken design (BBD) with three factors and three levels, including three replicates at the center point, were used for fitting a second-order response surface to provide a measure of process stability and inherent variability (Khani $\boldsymbol{e t} \boldsymbol{a l}$., 2015). The center points and parameters were selected according to Plackett-Burman design. In this model, the most significant independent variables, named $\left(\mathrm{X}_{1}\right),\left(\mathrm{X}_{2}\right)$ and $\left(\mathrm{X}_{3}\right)$ are included and each factor can be examined at the three different levels, low (-), high (+) and central or basal (0) as shown in Table2. All experiments were performed in triplicates. Here, three different variables including medium consisted of shaking $\left(X_{1}\right), \operatorname{starch}\left(X_{2}\right)$ and incubation temperature $\left(\mathrm{X}_{3}\right)$ were treated as independent variables. Fifteen trials and their observations (shown in the results section) were fitted to the following second order polynomial mode:

$Y=b_{0}+b_{1} X_{1}+b_{2} X_{2}+b_{3} X_{3}+b_{12} X_{1} X_{2}+b_{13} X_{1} X_{3}+$

$b_{23} X_{2} X_{3}+b_{11} X_{1}^{2}+b_{22} X_{2}^{2}+b_{33} X_{3}^{2}$

Where, $\mathrm{Y}$ is the dependent variable (EPS production); $\mathrm{X}_{1}, \mathrm{X}_{2}$ and $\mathrm{X}_{3}$ are the independent variables; $b_{0}$ is the regression coefficient at center point; $b_{1}, b_{2}$ and $b_{3}$ are linear coefficients; $b_{12} b_{13}$ and $b_{23}$ are second-order interaction coefficients; and $b_{11}$ and $b_{33}$ are quadratic coefficients. The values of the coefficients were calculated and the optimum concentrations were predicted using Minitab
16.2.4 (ref USA) software. The quality of the fit of the polynomial model equation was expressed by $\mathrm{R}^{2}$, the coefficient of determination.

\subsection{Purification of EPS by diethylaminoethyl-cellulose (DEAE- cellulose)}

The previously obtained precipitate was dissolved in distilled water and then lyophilized in a vacuum freeze dryer to obtain the crude polysaccharide. A sample of the polysaccharide was redissolved in distilled water, and then purified with the DEAEcellulose A52 column $(2.6 \mathrm{~cm} \times 60 \mathrm{~cm})$, which was equilibrated with distilled water. The polysaccharide was fractionated by stepwise elution with distilled water (Gabriela, et al., 2003; Liu, Lu, et al. 2015). Polysaccharide containing fractions were determined for the presence of the total sugar by phenol-sulfuric acid method (Dubois et al., 1956). The fractions containing sugar were pooled, concentrated by ultra-filtration, and precipitated with 2 volumes of ethanol, respectively.

\subsection{Characterization of exopolysaccharides produced by Pleurotus sapidus}

1-High Performance Liquid Chromatography Analysis:

Analysis of the carbohydrate in the filtrate was performed by using High Performance Liquid Chromatography (HPLC). Exopolysaccharides were hydrolyzed following the method of (Chen $\boldsymbol{e t}$ al., 2005). Sample separation was carried on a Shimpack VP-ODS C18 column $(250 \mathrm{~mm} \times$ $4.6 \mathrm{~mm}, 5 \mu \mathrm{m}$, Shimadzu, Kyoto, Japan) kept at $30{ }^{\circ} \mathrm{C}$. The mobile phase was composed of $0.1 \mathrm{~mol} / \mathrm{l}$ ammonium acetate (adjusted to $\mathrm{pH}$ 4.5 with acetic acid): acetonitrile (83:17, v/v). The flow rate was $1.0 \mathrm{ml} / \mathrm{min}$. The injection volume was $20 \mu 1$. 
2-FourierTransform-Infrared spectro-scopy FT-IR of EPSs produced from Pleurotus sapidus

The structure of EPS was investigated by FT-IR spectroscopic analyses using Fourier Transform Infrared Spectrophotometer (FT/IR4100, Japan). The purified EPS fractions (1 $\mathrm{mg}$ ) were ground with $300 \mathrm{mg} \mathrm{KBr}$ powder and then pressed into pellets for transform IR spectral measurement on a Mattson Instrument (Mattson Instruments, Inc., Madison, WI, USA) and the absorbance of samples was scanned from $400-4000 \mathrm{~cm}^{-1}$. The spectra were corrected for wavenumber-dependent signaldetection efficiency of the setup using a white light spectrum of a temperature calibrated tungsten band lamp (Shen et al., 2013).

\section{3- Nuclear Magnetic Resonance ( $\left.{ }^{1} \mathrm{HNMR}\right)$ of exopolysaccharides produced from Pleurotus sapidus.}

The exopolysaccharide was subjected to the proton $\left({ }^{1} \mathrm{H}\right)$ nuclear magnetic resonance (NMR) spectra and were recorded in deutrated dimethyl sulphoxide (DMSO-d6) on a Burker High Performance Digetal FT-NMR Spectrometer Avance $111400 \mathrm{MHz}$ (Centeral lab., Faculty of pharmacy, Egypt) (Kogan et al., 2002).

2.10. Applications of EPSs produced by $P$. sapidus

\section{Antioxidant activity:}

Total antioxidant activity of purified exopolysaccharides was estimated according to the method described by (Thaipong et al., 2006) using different exopolysaccharides concentrations $(0.0,0.25,0.50,1,2 \mathrm{mg})$ each dissolved in $1 \mathrm{ml}$ distilled $\mathrm{H}_{2} \mathrm{O}$.

\subsection{STATISTICAL ANALYSIS}

Data were expressed as mean \pm S.D. $(n=3)$. Experimental data were statistically subjected to analysis of variance (ANOVA) using
Minitab 16.2.4 (ref USA) software to evaluate significant differences at probability level of $p$ $<0.05$.

\section{RESULTS AND DISCUSSION}

3.1. Effect of different media on exopolysacchari- des production and mycelial dry weight of Pleurotus sapidus

Figure 1 showed that Glucose Yeast peptone liquid medium (GYP) was the best medium for exopolysaccharide extract and high mycelial biomass of Pleurotus sapidus production which gave $1.138 \pm 0.012$ and 0.286 $\pm 0.010 \mathrm{mg} / \mathrm{ml}$ respectively. Among different growing agar media used in this investigation are GYP, PDA, MEA, and WEA; Glucose Yeast Pepton media has proved to be the best media for the mycelial growth and EPS production of Pleurotus sapidus followed by PDA with a slight difference. These results were agreed with Latha and baskar, (2014) who studied the effect of different media on production of polysaccharides from oyster mushroom Pleurotus florida and Hypsizygus ulmarius and found that that glucose yeast peptone (GYP) media was the best media. This difference of EPS production and mycelial growth on different media may be due to availability of different carbon sources and availability of other required nutrients for mushroom Pleurotus sapidus in GYP medium.

\subsection{Effect of Static and Shaking condition} on both EPS, IPS production and mycelial dry weight of Pleurotus sapidus

It was evident that Exopolysaccharides and mycelial dry weight in case of shaking is higher than that of static condition which were $1.795 \pm 0.003$ and $1.183 \pm 0.066 \mathrm{mg} / \mathrm{ml}$ respectively (Fig. 2). This was consistent with finding of Anike et al., (2015) who explained that shaked fermentation was higher than static in production of exopolysaccharides from Lentinus squarrosulus. This indicates that the 
higher aeration (agitation) was an efficient strategy for enhanced EPS production (Chiu et al., 2008). Agitation enhances mixing in the culturing broth, which is necessary to provide the nutrient and oxygen supply required for the growth of fungi and subsequently increase the production of biomass and EPS (Xu et al., 2006).

\subsection{Optimization of EPSs production using Plackett-Burman experimental design}

The Plackett-Burman design is an important tool in screening the effects of variables process on yield; It can significantly reduce the number of repetitive experiments to be conducted in a further optimization study, using a response surface methodology (Ekpenyong et al., 2017). The effect of the variables on EPS production was determined by conducting twenty experiments given by the model (Table 1). All experiments were performed in three replica and the average results as percentage of EPS production are presented in (Table 1) that show the maximum production of EPS from Pleurotus sapidus was obtained on trial 15 (+ve concentration of glucose, starch, peptone, yeast extract, $\mathrm{KH}_{2} \mathrm{PO}_{4}$, stearic acid and shaking, while -ve concentration of $\mathrm{pH}$, incubation time, temperature, sucrose, omega 3 and inoculum size) (Table 1). The main effect of each variable was calculated as the difference between both averages of measurements made at the high level $(+)$ and at the low level (-) of that factor. The results of main effect are presented in Fig. (3). The results indicated that the presence of high levels of shaking, starch, glucose, $\mathrm{KH}_{2} \mathrm{PO}_{4}$, stearic acid, sucrose and maltose in the basal medium positively affected EPS production. These results are confirmed from the Pareto chart as shown in Fig. (4), which indicates higher effects presented in the upper portion and then progress down to the lower effects.
It was deduced from Fig. (4) that the shaking condition was the most significant variable that affected EPS production, followed by starch and temperature, respectively. These variables were examined more thoroughly by applying the Box-Behnken design.

\subsection{Optimization of EPS production by Box-Behnken design}

In order to approach the optimum response region of EPS production, the effective independent variables including shaking $\left(\mathrm{X}_{1}\right)$, starch concentration $\left(\mathrm{X}_{2}\right)$ and temperature $\left(\mathrm{X}_{3}\right)$ suggested by the PlackettBurman design were further investigated, each at three levels (,- 0 and + ) according to the Box and Behnken design (Box and Behnken, 1960), (Table 2). However, glucose (40) $\mathrm{gl}^{-1}$, sucrose (30) $\mathrm{gl}^{-1}$, maltose (30) $\mathrm{gl}^{-1}$, peptone (7) $\mathrm{gl}^{-1}$, yeast extract (5) $\mathrm{gl}^{-1}$, $\mathrm{KH}_{2} \mathrm{PO}_{4}$ (1) $\mathrm{gl}^{-1}$, stearic acid (2) $\mathrm{gl}^{-1}$, initial $\mathrm{pH}$ (4.5), incubation period (10 days) and inoculum size (1disc) were treated as constant factors. (Table 2) represents the design matrix of the coded variables together with the experimental results of EPS production. All cultures were performed in triplicate and the average of the observations was used.

As shown in Table (2), the highest EPS production records $(8.792,8.827$ and 8.779$)$ $\mathrm{mg} / \mathrm{l}$ which were achieved by the trials number 13,14 and 15 , respectively, $25^{\circ} \mathrm{C}$. On the other hand, it is clear that the lowest EPS production was (7.193, 7.200 and 7.207) $\mathrm{mg} / \mathrm{l}$ which were achieved by the trials number 6,4 and 1 respectively, $30^{\circ} \mathrm{C}$.

For a precise prediction of the optimal point, a second order polynomial function was fitted to the EPS production results of the applied Box-Behnken experiment. Using Minitab 16.2.4 (ref USA) software it has obtained a value for coefficient of determination $\mathrm{R}^{2}$ of 0.99 .75 , which indicates that $99.75 \%$ of the variability of the response 
could be explained by the model and about $0.25 \%$ of the total variation cannot be explained by this model.

According to the obtained statistical analysis results, the correlation between the response and the three independent variables can be described by the following equation (2): equation (2)

\section{$Y=-46.1934+0.4589 X_{1}+0.5761 X_{2}+0.9578 X_{3}-$ $0.0007 X_{1} X_{2}+0.0020 X_{1} X_{3}+0.0006 X_{2} X_{3}-$ $0.0016 X_{1}^{2}-0.0079 X_{2}^{2}-0.0252 X_{3}^{2}$}

Where $\mathrm{Y}$ is the product of EPS (dependent variable); $X_{1}, X_{2}$ and $X_{3}$ are levels of shaking, starch and temperature, respectively. The degree of fitting of the model is relatively high as the calculated coefficient of determination $\left(\mathrm{R}^{2}\right)$ was 0.9975. Also, the Predictive R-Square was $96.30 \%$, which concluded that these values are in reasonable agreement with the Adjustive R-Squared of $99.29 \%$, indicating that a good agreement between the experimental and predicted values on EPS production. The closer the value of $\mathrm{R}$ is to 1 , the better is the correlation between the measured and the predicted values. This value indicates a high degree of correlation between the experimental and the predicted values.

Furthermore, solving the model according to the data obtained from (Table 2) revealed an optimum response at $X_{1}=150, X_{2}$ $=30$ and $\mathrm{X}_{3}=25$ with a predicted $\mathrm{Y}$ (response) of $8.8026 \mathrm{mg} / \mathrm{l}$. Thus, according to the results of the two optimization experiments, an optimum response (EPS production) is predicted under the following fermentation condition: glucose $40 \mathrm{gl}^{-1}$; sucrose $30 \mathrm{gl}^{-1}$; starch $30 \mathrm{gl}^{-1}$; maltose $30 \mathrm{gl}^{-1}$; peptone, $7 \mathrm{gl}^{-1}$; $\mathrm{KH}_{2} \mathrm{PO}_{4} 1 \mathrm{gl}^{-1}$; stearic acid $2 \mathrm{gl}^{-1}$; yeast extract $5 \mathrm{gl}^{-1}$; temperature $25{ }^{\circ} \mathrm{C}$; shaking $150 \mathrm{rpm}$; initial $\mathrm{pH} 4.5$; inoculum size 1disc; and an incubation period of 10 days.
In addition, the simultaneous effects of the three independent factors on each response were revealed by three-dimensional graphs generated by Minitab 16.2.4 (ref USA) software. As shown in the surface plots and their corresponding contour plots of the BoxBehnken design variations in shaking $\left(\mathrm{X}_{\mathrm{I}}\right)$, starch $\left(\mathrm{X}_{2}\right)$ and temperature $\left(\mathrm{X}_{3}\right)$ within the examined concentration ranges and under the present experimental conditions, were clearly effective. Figs. (5, 6 and 7) showed the influences of variations in shaking, starch and temperature on the experimental fungus with respect to EPS production. From this figures, it can be suggested that, up to approximately 25 ${ }^{\circ} \mathrm{C}$, the more the temperature lead to decrease in the EPS production in the medium. It seems likely that increasing the speed of shaker to about $150 \mathrm{rpm}$ would allow more EPS production. However, an optimum level of starch appears to be $30 \mathrm{gl}^{-1}$.

Thus, according to the results of the two optimization experiments, an optimum response (EPS production) is predicted under the following fermentation condition $\mathrm{gl}^{-1}$ : glucose 40; sucrose 30; starch 30.1; maltose 30; peptone $7 ; \mathrm{KH}_{2} \mathrm{PO}_{4} 1$; stearic acid 2; yeast extract 5; temperature $25.2{ }^{\circ} \mathrm{C}$; shaking 148.9 rpm; initial $\mathrm{pH} 4.5$; inoculum size 1disc; and an incubation period of 10 days. 


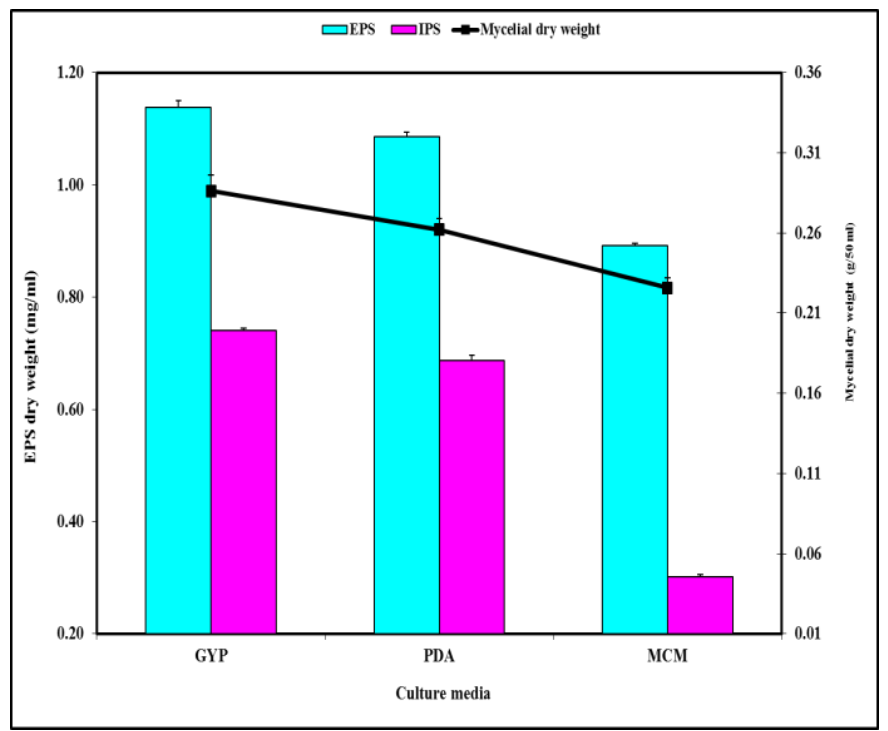

Fig. (1): Effect of different media on exopolysaccharides, endopolysaccharide production and mycelial dry weight of Pleurotus sapidus.

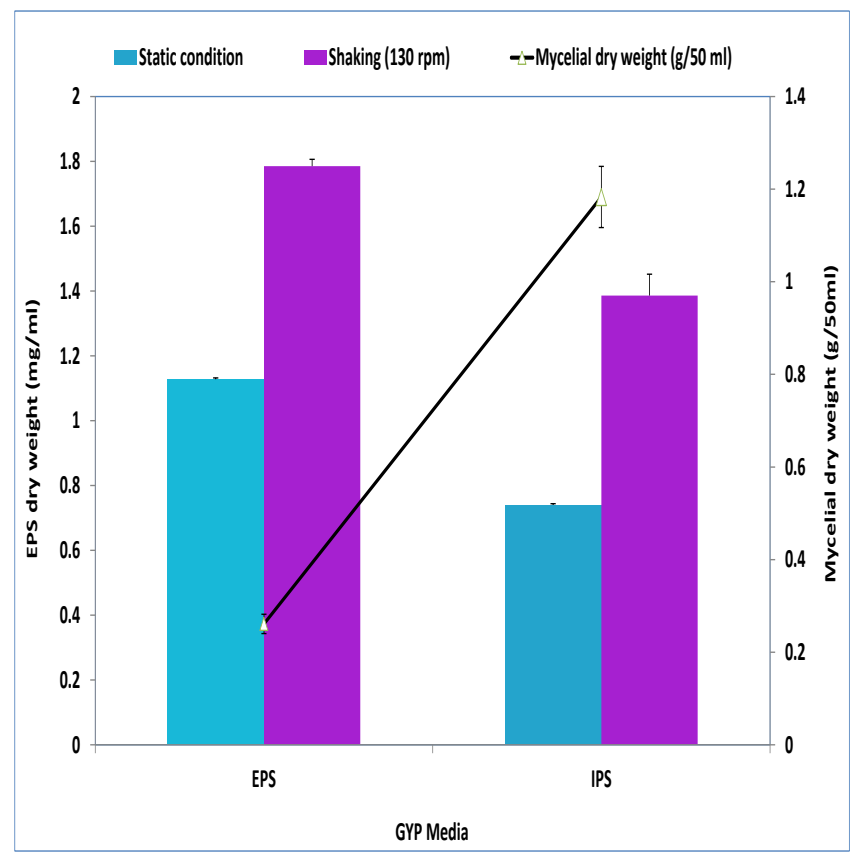

Fig. (2): Effect of Static and Shaking condition on both EPS, IPS production and mycelial dry weight of Pleurotus sapidus:

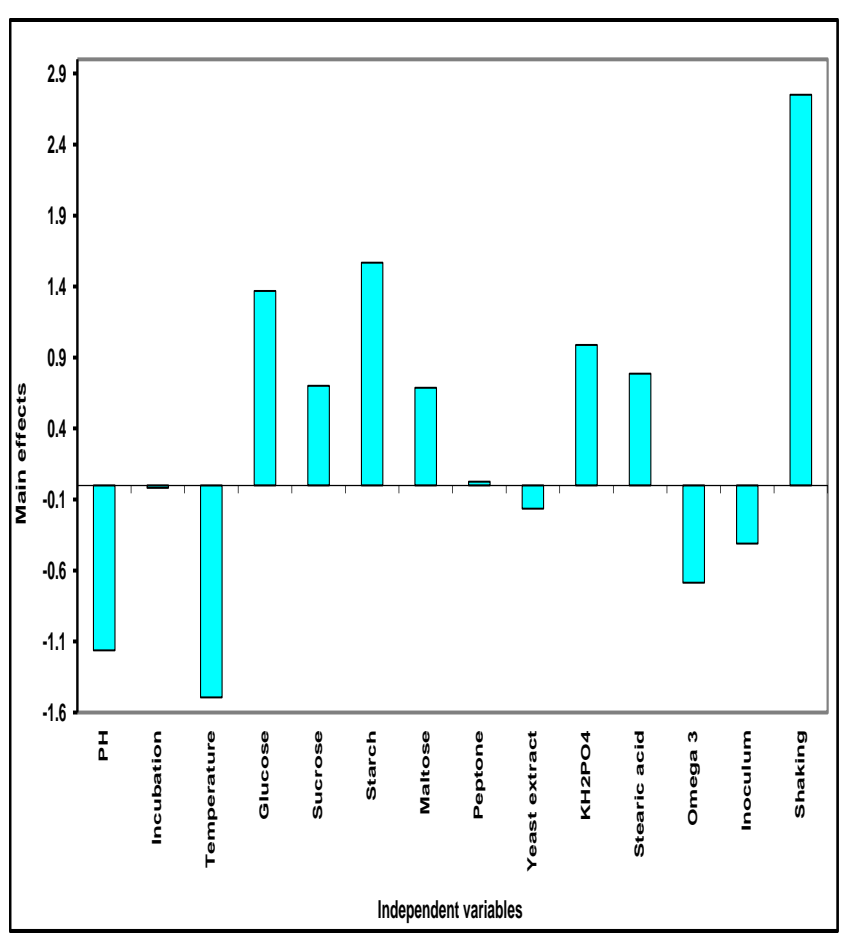

Fig. (3): Main effects of independent variables examined in Plackett-Burman design.

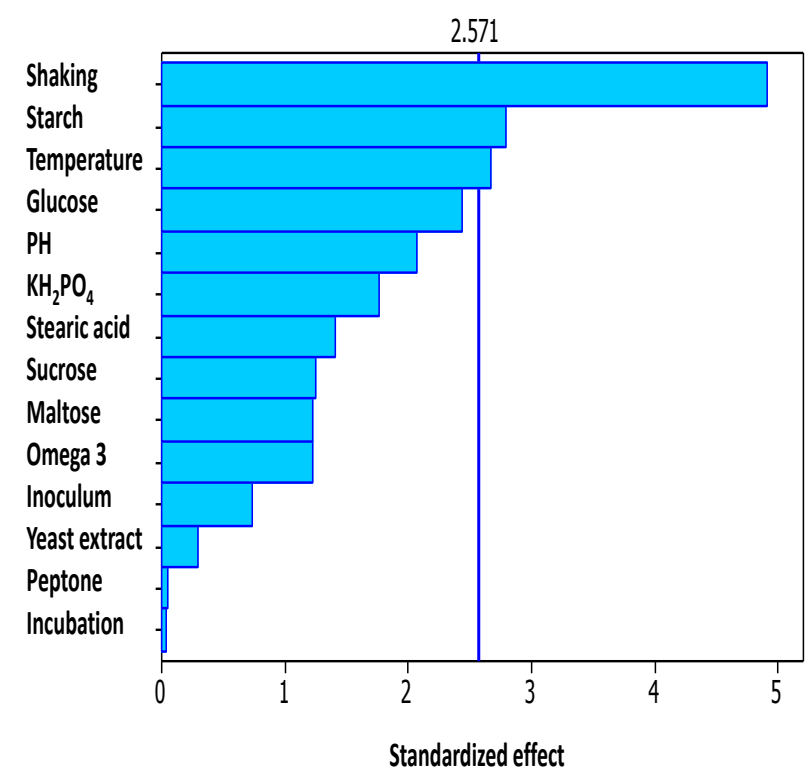

Fig. (4): Pareto chart of the standardized effects of EPS dry weight $(\mathrm{mg} / \mathrm{ml})$ examined in Placket-Burmann design (Alpha $=0.05)$. 
Table (1): Response to Plackett Burman design of 14 independent variables in 20 trials (data were average of three replica \pm SD)

\begin{tabular}{|c|c|c|c|c|c|c|c|c|c|c|c|c|c|c|c|c|}
\hline$\frac{\frac{\omega}{\pi}}{\stackrel{\sigma}{\frac{\sigma}{2}}}$ & $\frac{T}{2}$ & 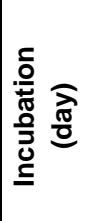 & 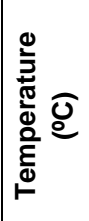 & $\begin{array}{l}\frac{T}{0} \\
\frac{1}{0} \\
\Phi \\
00 \\
\frac{0}{0} \\
0\end{array}$ & $\begin{array}{l}\frac{1}{1} \\
\frac{7}{0} \\
0 \\
0 \\
0 \\
0 \\
0 \\
0\end{array}$ & 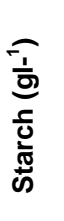 & 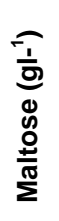 & 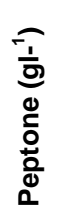 & 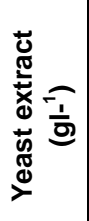 & $\begin{array}{l}-1 \\
\frac{1}{0} \\
\frac{0}{0} \\
\frac{1}{2} \\
\frac{1}{2}\end{array}$ & 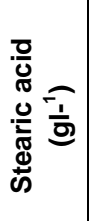 & 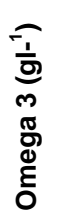 & 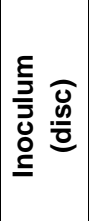 & 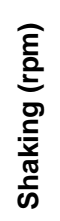 & 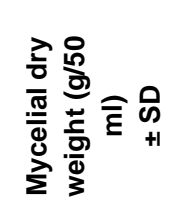 & 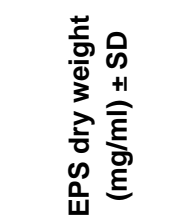 \\
\hline 1 & + & - & + & + & - & - & - & - & + & - & + & - & + & + & $1.439 \pm 0.013$ & $0.501 \pm 0.005$ \\
\hline 2 & + & + & - & + & + & - & - & - & - & + & - & + & - & + & $0.698 \pm 0.006$ & $3.966 \pm 0.009$ \\
\hline 3 & - & + & + & - & + & + & - & - & - & - & + & - & + & - & $2.190 \pm 0.245$ & $0.908 \pm 0.286$ \\
\hline 4 & - & - & + & + & - & + & + & - & - & - & - & + & - & + & $1.125 \pm 0.192$ & $3.143 \pm 0.407$ \\
\hline 5 & + & - & - & + & + & - & + & + & - & - & - & - & + & - & $1.270 \pm 0.036$ & $1.200 \pm 0.016$ \\
\hline 6 & + & + & - & - & + & + & - & + & + & - & - & - & - & + & $0.170 \pm 0.016$ & $2.103 \pm 0.002$ \\
\hline 7 & + & + & + & - & - & + & + & - & + & + & - & - & - & - & $1.570 \pm 0.073$ & $0.644 \pm 0.056$ \\
\hline 8 & + & + & + & + & - & - & + & + & - & + & + & - & - & - & $0.947 \pm 0.095$ & $0.239 \pm 0.003$ \\
\hline 9 & - & + & + & + & + & - & - & + & + & - & + & + & - & - & $2.323 \pm 0.306$ & $0.586 \pm 0.045$ \\
\hline 10 & + & - & + & + & + & + & - & - & + & + & - & + & + & - & $2.130 \pm 0.191$ & $0.632 \pm 0.091$ \\
\hline 11 & - & + & - & + & + & + & + & - & - & + & + & - & + & + & $1.231 \pm 0.077$ & $7.944 \pm 0.026$ \\
\hline 12 & + & - & + & - & + & + & + & + & - & - & + & + & - & + & $1.530 \pm 0.180$ & $3.523 \pm 0.12$ \\
\hline 13 & - & + & - & + & - & + & + & + & + & - & - & + & + & - & $1.083 \pm 0.078$ & $1.848 \pm 0.751$ \\
\hline 14 & - & - & + & - & + & - & + & + & + & + & - & - & + & + & $1.543 \pm 0.039$ & $2.936 \pm 0.421$ \\
\hline 15 & - & - & - & + & - & + & - & + & + & + & + & - & - & + & $1.220 \pm 0.269$ & $7.966 \pm 0.005$ \\
\hline 16 & - & - & - & - & + & - & + & - & + & + & + & + & - & - & $1.653 \pm 0.241$ & $0.888 \pm 0.111$ \\
\hline 17 & + & - & - & - & - & + & - & + & - & + & + & + & + & - & $0.970 \pm 0.016$ & $0.307 \pm 0.034$ \\
\hline 18 & + & + & - & - & - & - & + & - & + & - & + & + & + & + & $1.580 \pm 0.289$ & $2.253 \pm 0.165$ \\
\hline 19 & - & + & + & - & - & - & - & + & - & + & - & + & + & + & $0.930 \pm 0.033$ & $0.603 \pm 0.005$ \\
\hline 20 & - & - & - & - & - & - & - & - & - & - & - & - & - & - & $0.263 \pm 0.029$ & $0.17 \pm 0.008$ \\
\hline
\end{tabular}

Table (2): Independent variables studied by BoxBehnken design using 3 factors in 15 trials

\begin{tabular}{||c|c|c|c|c||}
\hline Trials & $\begin{array}{c}\text { Shaking } \\
(\mathrm{rpm})\end{array}$ & $\begin{array}{c}\text { Starch } \\
\left(\mathrm{gl}{ }^{-1}\right)\end{array}$ & $\begin{array}{c}\text { Temperature } \\
\left({ }^{\circ} \mathrm{C}\right)\end{array}$ & $\begin{array}{c}\text { EPS } \\
(\mathrm{mg} / \mathrm{ml}) \pm \mathrm{SD}\end{array}$ \\
\hline 1 & $(-) 130$ & $(-) 20$ & $(+) 30$ & $7.207 \pm 0.016$ \\
\hline 2 & $(+) 170$ & $(-) 20$ & $(0) 25$ & $7.399 \pm 0.005$ \\
\hline 3 & $(-) 130$ & $(+) 40$ & $(0) 25$ & $7.607 \pm 0.005$ \\
\hline 4 & $(+) 170$ & $(+) 40$ & $(+) 30$ & $7.200 \pm 0.016$ \\
\hline 5 & $(-) 130$ & $(0) 30$ & $(-) 20$ & $7.743 \pm 0.022$ \\
\hline 6 & $(+) 170$ & $(0) 30$ & $(+) 30$ & $7.193 \pm 0.001$ \\
\hline 7 & $(-) 130$ & $(0) 30$ & $(0) 25$ & $7.439 \pm 0.002$ \\
\hline 8 & $(+) 170$ & $(0) 30$ & $(-) 20$ & $7.689 \pm 0.008$ \\
\hline 9 & $(0) 150$ & $(-) 20$ & $(-) 20$ & $7.324 \pm 0.012$ \\
\hline 10 & $(0) 150$ & $(+) 40$ & $(+) 30$ & $7.248 \pm 0.003$ \\
\hline 11 & $(0) 150$ & $(-) 20$ & $(0) 25$ & $7.445 \pm 0.014$ \\
\hline 12 & $(0) 150$ & $(+) 40$ & $(-) 20$ & $7.484 \pm 0.003$ \\
\hline 13 & $(0) 150$ & $(0) 30$ & $(0) 25$ & $8.792 \pm 0.031$ \\
\hline 14 & $(0) 150$ & $(0) 30$ & $(0) 25$ & $8.827 \pm 0.032$ \\
\hline 15 & $(0) 150$ & $(0) 30$ & $(0) 25$ & $8.779 \pm 0.017$ \\
\hline \hline
\end{tabular}
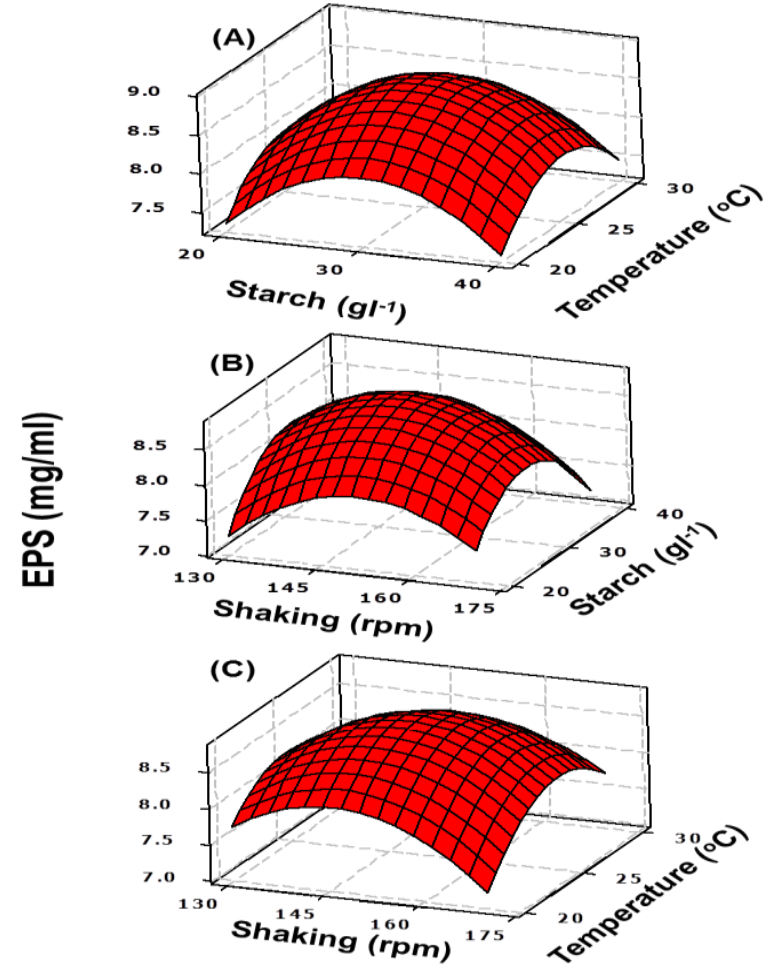

Fig. (5): Response surface plots of EPS production by Pleurotus Sapidus using independent variables; (A) temperature and starch, (B) starch and shaking and (C) temperature and shaking. 

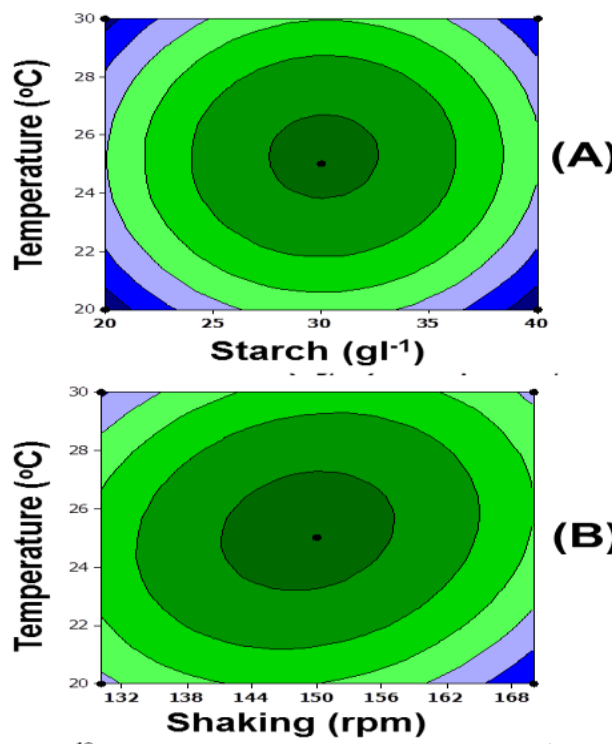

\section{EPS ( $\mathbf{m g} / \mathbf{m I})$}

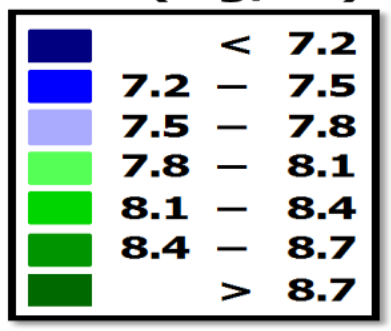

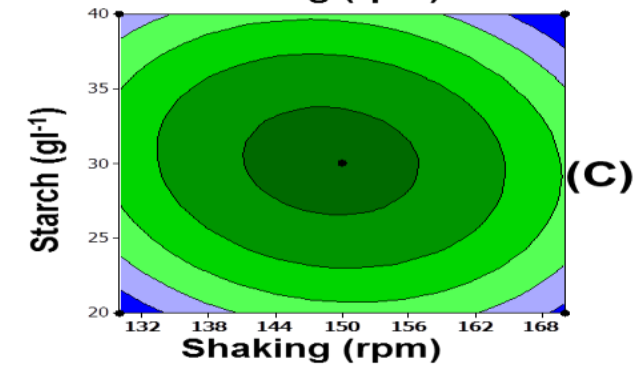

Fig. (6): Contour Plot of EPS (mg/ml) production against; (A) temperature and starch, (B) temperature and shaking, and (C) starch and shaking

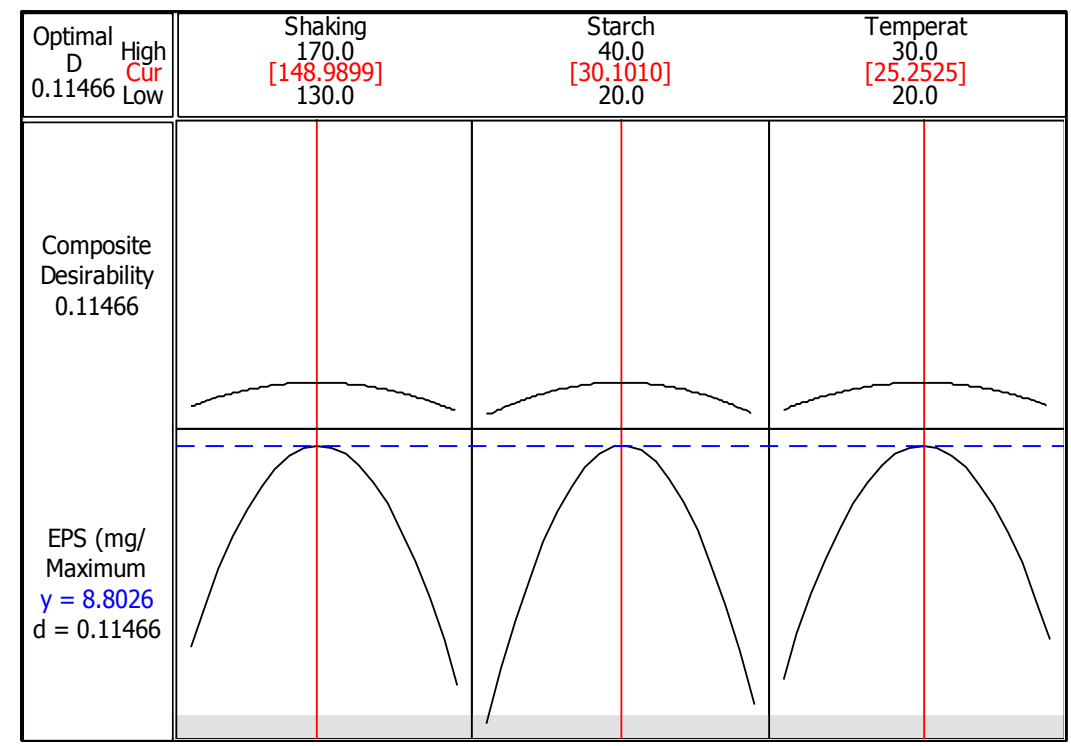

Fig. (7): Optimization plot of EPS production by Pleurotus Sapidus using Box-Behnken design. 
Table (3): ANOVA for process variables.

\begin{tabular}{|c|c|c|c|c|c|c|}
\hline Source & DF & Seq SS & Adj SS & Adj MS & F-value & P-value \\
\hline Regression & 9 & 4.99094 & 4.99094 & 0.55455 & 219.07 & 0.000 \\
\hline Linear & 3 & 0.07431 & 0.07431 & 0.02477 & 9.78 & 0.016 \\
\hline Shaking & 1 & 0.03308 & 0.03308 & 0.03308 & 13.07 & 0.015 \\
\hline Starch & 1 & 0.00336 & 0.00336 & 0.00336 & 1.33 & 0.301 \\
\hline Temperature & 1 & 0.03787 & 0.03787 & 0.03787 & 14.96 & 0.012 \\
\hline Square & 3 & 4.66396 & 4.66396 & 1.55465 & 614.16 & 0.000 \\
\hline Shaking*Shaking & 1 & 1.13389 & 1.57363 & 1.57363 & 621.65 & 0.000 \\
\hline Starch*Starch & 1 & 2.06226 & 2.32561 & 2.32561 & 918.72 & 0.000 \\
\hline Temperature*Temperature & 1 & 1.46780 & 1.46780 & 1.46780 & 579.85 & 0.000 \\
\hline Interaction & 3 & 0.25267 & 0.25267 & 0.08422 & 33.27 & 0.001 \\
\hline Shaking*Starch & 1 & 0.08960 & 0.08960 & 0.08960 & 35.40 & 0.002 \\
\hline Shaking*Temperature & 1 & 0.15979 & 0.15979 & 0.15979 & 63.12 & 0.001 \\
\hline Starch*Temperature & 1 & 0.00329 & 0.00329 & 0.00329 & 1.30 & 0.306 \\
\hline Residual Error & 5 & 0.01266 & 0.01266 & 0.00253 & & \\
\hline Lack-of-Fit & 3 & 0.01140 & 0.01140 & 0.00380 & 6.03 & 0.145 \\
\hline Pure Error & 2 & 0.00126 & 0.00126 & 0.00063 & & \\
\hline Total & 14 & 5.00359 & & & & \\
\hline
\end{tabular}

\subsection{Characterization} exopolysaccharides Pleurotus sapidus:

Exopolysaccharides were subjected to High Performance Liquid Chromatography analysis (HPLC). The HPLC chromatograph (Figure 8) showed that they consist of five peaks that referred to presence of $\beta-(1 \rightarrow 3)$ glucans, $\beta-(1 \rightarrow 6)$ glucans branched, Chitin, Mannans and Galactans with different concentrations in EPS. For $1 \mathrm{mg}$ of EPS structure analysis, the concentrations of $\beta$ $(1 \rightarrow 3)$ glucans, $\beta-(1 \rightarrow 6)$ glucans branched, Chitin, Mannans and Galactans were $25.40 \%$, $15.60 \%, 19.20 \%, 22.20 \%, 17.60 \%$ respectively.
According to Jahan and Singh (2019) mushrooms are a good source of insoluble fiber in the form of chitin (polymer of $\mathrm{N}$-acetylglucosamine) and non-starch polysaccharides like $\beta$-glucans. Also, According to Khan and Tania (2012) the carbohydrates in Pleurotus spp. are mainly in the form of polysaccharides or glycoproteins. The most abundant polysaccharides are chitin, $\alpha$ - and $\beta$-glucans, and other hemicelluloses (e.g., mannans, xylans, and galactans). 


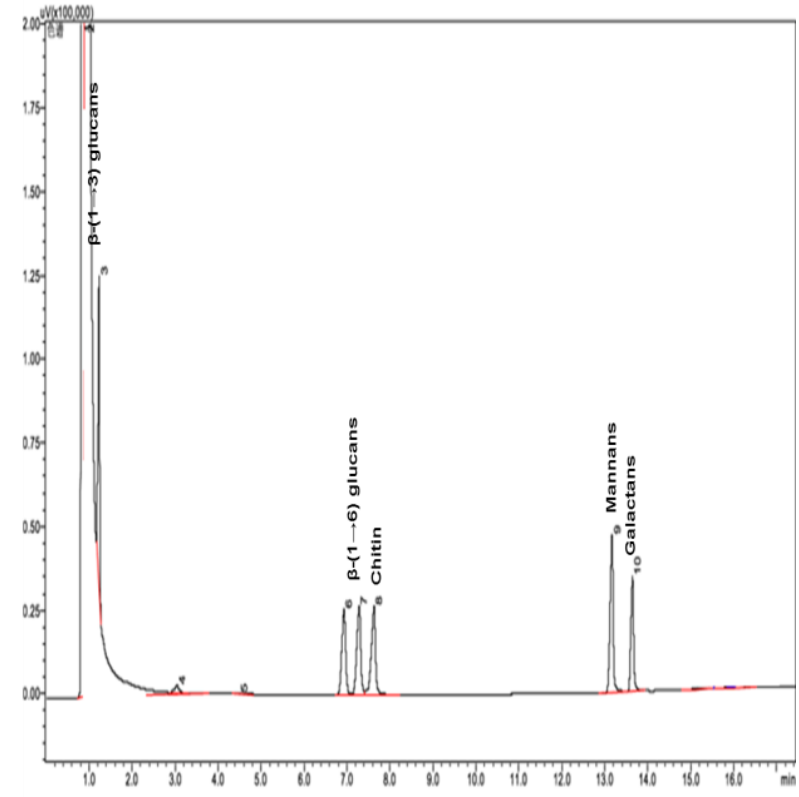

Fig. (8): HPLC of monomer of exopolysaccharides in culture filtrate produced by pleurotus sapidus.

\subsection{DPPH scavenging activity of exopolysacch -arides}

DPPH method is usually to evaluate antioxidant activity of various natural compounds by reducing stable DPPH radicals to yellow-colored diphenylpicryl-hydrazine. DPPH radical scavenging ability is responsible for hydrogen donating efficiency of antioxidants. As shown in (Fig. 9) DPPH radical scavenging activity of endopolysaccharides increased gradually with increasing concentration. At $2 \mathrm{mg} / \mathrm{ml}$ scavenging effects of EPS were 94\%. These findings also agree with findings by Jeena $\boldsymbol{e t}$ al. (2016).

The present results also agree with the results of Li et al. (2012) who suggested that all the polysaccharides from Hypsizygus marmoreus, Lentinus edodes, Russula vinosa Lindblad, Hohenbuehelia serotina, Auricularia auricula and Hericium erinaceus had significant antioxidant capacities (ranged from $18.54 \%$ to $100 \%$ ) at concentration of $20 \mathrm{mg} / \mathrm{ml}$. Also, Zhao et al. (2005) reported that radical scavenging ability is responsible for hydrogen donating efficiency of antioxidants.Therefore, the antioxidant activity may be attributed to the proton donating ability, indicating that it may contain lots of reductones to react with radicals to stabilize and terminate radical chain reactions.

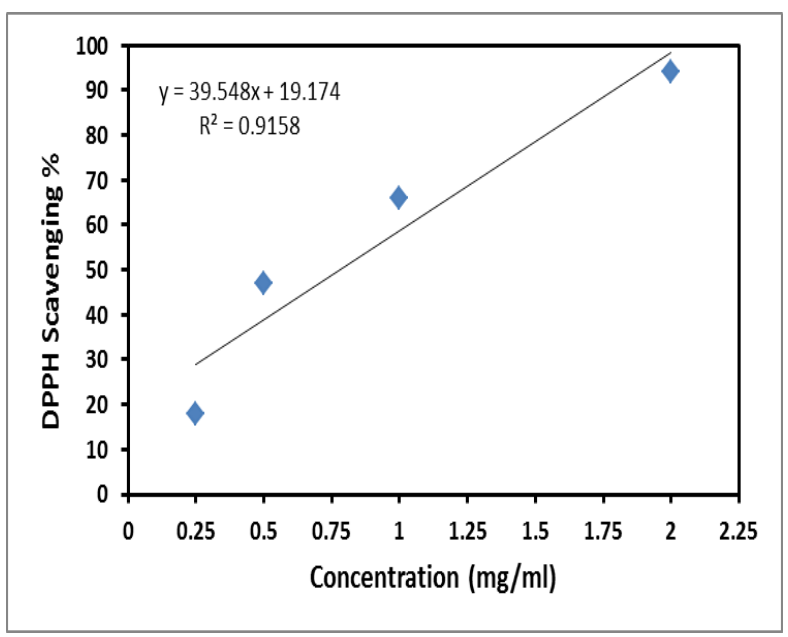

Fig. (9): Antioxidant activity of exopolysaccharides production from Pleurotus sapidus.

\subsection{Anti-tumour activity of Pleurotus sapidus EPS}

In the present study, the growth inhibitory effects of the EPS obtained from $P$. sapidus against human colon cancer cell (Caco-2) were examined. The control (Caco2 ) cells viability was assessed as $100 \%$. The inhibitory effect was estimated using different concentration (10000, 5000, 2500, 1250, 625, $312.5,156.25$ and $78.125 \mathrm{mg} / \mathrm{ml}$ ) of EPS on both cell line included. Current results showed that the produced EPS exhibited various degree of antitumor effect toward the tested cell lines with increasing concentrations of EPS resulted in increased rates of tumour inhibition. EPS presented anti-proliferative activity at dosage 10000 $\mathrm{mg} / \mathrm{ml}$ where inhibit $91 \%$ of tumour viability cells of colon as shown in (Fig. 10). The $\mathrm{IC}_{50}$ for colon was $185.021 \mathrm{mg} / \mathrm{ml}$. The effects of EPS on cell line were exhibited in (Fig.11) in which at concentration $78.125 \mathrm{mg} / \mathrm{ml}$ there is slightly disintegration of cells, at 156.25 $\mathrm{mg} / \mathrm{ml}$ disintegration of cells increased, at 
$312.5 \mathrm{mg} / \mathrm{ml}$ partial disintegration and at $10000 \mathrm{mg} / \mathrm{ml}$ increased lysis percentage, subsequently the number of individual tumour cell decreased. In what refers to the polysaccharides from Pleurotus spp., Facchini et al. (2014) reported the efficacy of a polysaccharide fraction obtained from the mycelium of $P$. ostreatus with NH4-oxalate at $100^{\circ} \mathrm{C}$ inhibiting the development of Ehrlich Tumour (ET) and Sarcoma 180 (S-180).

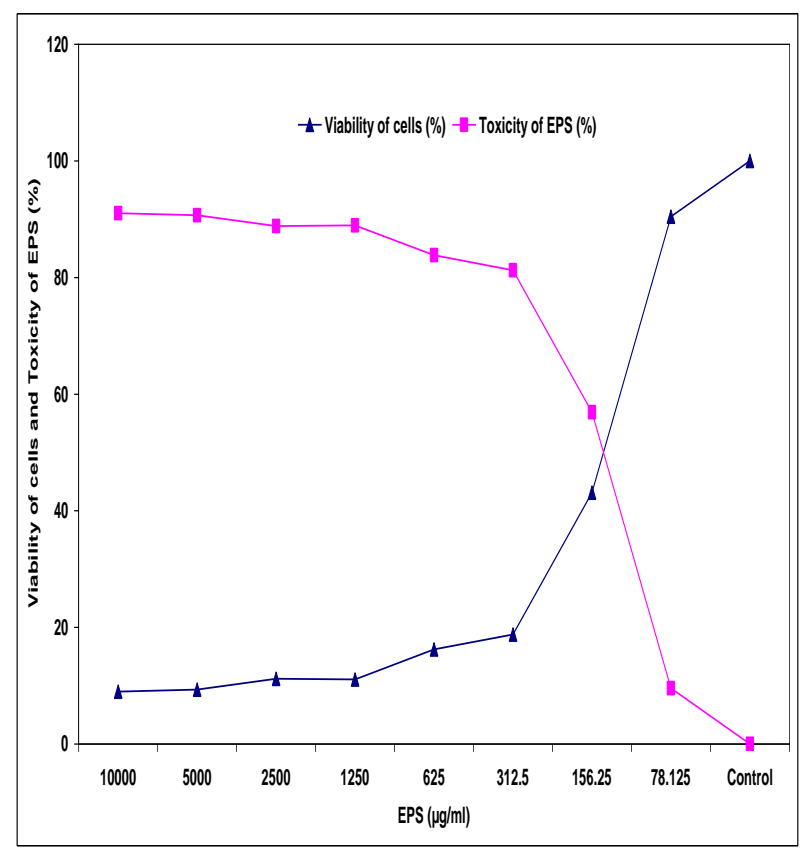

Fig. (10): Effect of EPS from Pleurotus sapidus (toxicity) on survival Caco-2 at different concentration in relation to cell viability of tumor.
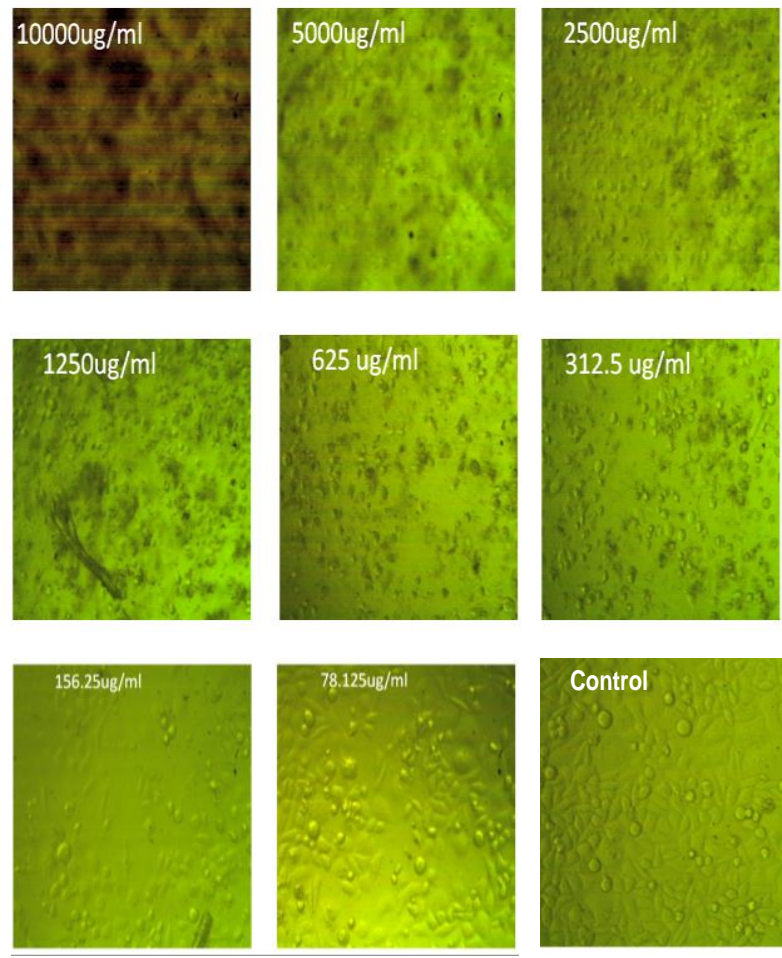

Fig. (11): Effect of EPS produced by Pleurotus sapidus on Caco-2 cells at different concentrations.

\subsection{Antiviral activity of Pleurotus sapidus EPS}

In the present study, the growth inhibitory effects of the EPS obtained from $P$. sapidus against HAV (Hepatitis A Virus) was examined. The HAV was injected to Vero cell causing $53.8 \%$ toxicity of Vero cell which represents $100 \%$ of its actual virulent power. By application of EPS crude extract, the toxicity of virus to Vero cell became $48.3 \%$ which represent $83 \%$ of viral activity. So, the EPS of $P$. sapidus exhibited antiviral activity in percentage of $16.8 \%$.These data are shown in (Fig.12). 
—Viral activity (\%) — Antiviral effect (\%)

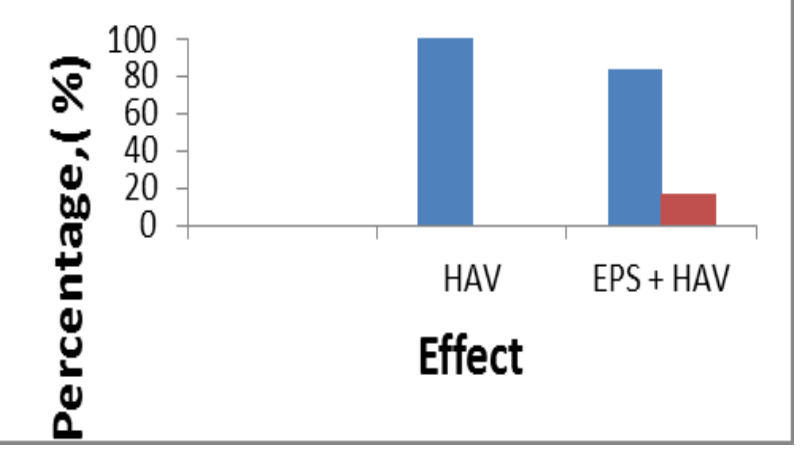

Fig. (12): Effect of different concentrations of EPS obtained from P. Sapidus on survival HAV (Dilution used $=78.125 \mathrm{mg} / \mathrm{ml}$ ).

\section{Conclusion and Recommendation:}

The recorded results support the efficiency of multi-factorial experimental designs in elucidating the significant factors and predicting their optimum settings for achieving EPS maximum productivity. The current study indicates that exopolysaccharides extracted from P.sapidus has efficient scavenging activity.

It can be recommended that supplementation of natural products as $P$. sapidus mushroom is an important powerful anti tumor, antioxidant, antiviral and can be used for medical purposes. Future studies are needed to evaluate the feasibility of $P$. sapidus extract for developing potent antitumor, antioxidant drugs and detect their biological activities.

\section{References}

Anike, F. N.; Omoanghe, S.; Isikhuemhen, O. S.; Blum, D. and Neda, H. (2015): Nutrient requirements and fermentation conditions for mycelia and crude exopolysaccharides production by Lentinus squarrosulus. Advan. in Biosci. and Biotechnol., 6(08): 526-536.

Bellettini, M.B.; Fiorda, F.A.; Maieves, H.A.; Teixeira, G.L.; Avila, S.; Hornung, P.S.; Junior, A.M. and Ribani, R.H. (2016). Factors affecting mushroom
Pleurotus spp. Saudi J. Biol. Sci., 26 (4) : 633-646.

Berg, J. M. (2007). Biochemistry, 6th ed. New York: W.H. Freeman and Company. p. 69.

Box, G. E. P.; Behnken, D. W., (1960): Some new three-level designs for the study of quantitative variables. Technometrics, 2: 455-75.

Chen H.Q.; Chen X. M.; Chen T. X.; Xu X. M.; Jin Z. Y., (2011): Optimization of solid-state medium for the production of inulinase by Aspergillus ficuum JNSP506 using response surface methodology. Carbohydr Polym. 86(1): 249-254.

Chen, Q.; Qi, C.; Peng, G.; Liu,Y.; Zhang, X. and Meng, Z. (2018). Immuneenhancing effects of a polysaccharide PRG1-1 from Russula griseocarnosa on RAW264.7 macrophage cells via the MAPK and NF- $\mathrm{KB}$ signalling pathways. Food Agr. Immunol., 29(1): 833-844.

Chiu-Yeh W.U. ; Zeng-Chin Liang; Chian-Ping L.U. and Shiu-Hsiung W.U.,(2008): Effect of Carbon and Nitrogen Sources on the Production and Carbohydrate Composition of Exopolysaccharide by Submerged Culture of Pleurotus citrinopileatus. J. of Food and Drug Analysis, 16(2): 61-67.

Deveci, E.; Cayan, F.; $\quad$ Tel-Cayan, G.; Duru M. E. (2019): Structural characterization and determination of biological activities for different polysaccharides extracted from tree mushroom species. J. Food Biochem., 43(9):1-13

Dubois, M.; Gilles, K. A.; Hamilton, J.K.; Rebers, P. A. and Smith, F. (1956). Colorimetric method for determination of sugars and related substances. Anal. Chem., 28(3): 350-356.

Ekpenyong, M.G.; Antia, S.P.; Asitok, A.D.; Ekpo, P.O., (2017): Plackett- Burman Design and Response surface optimization of medium trace nutrients for glycolipopeptide biosurfactant 
production. Iranian Biomed J. 21(4): 249-260.

ELshamy, A.R. and Nehad, E.A. (2010). Optimization of polysaccharide production by Alterneria alternate. gate2 biotech. com., 1(9): 1-6.

Facchini, J. M.; Alves, E. P.; Aguilera, C.; Gern, R. M. M.; Silveira, M. L. L.; Wisbeck, E.; Furlan, S. A. (2014): Antitumor activity of Pleurotus ostreatus polysaccharide fractions on ehrlich tumor and sarcoma 180.International Journal of Biological Macro-molecules, 68: 72-77.

Fontes, A.; Pages, M.A.; Oliveira, P.J.; Santos, J.R; Zischka,H. and Azul, A.M. (2019). Antioxidant versus Pro-Apoptotic effects of mushroom-enriched diets on mitochondria in liver disease. Int. J. Mol. Sci., 16(20): 1-35.

Gabriela, C.; Norma, S.; Bessio, M.I.; Fernando, F.; Hugo, M. (2003): Quantitative determination of pneumococcal capsular polysaccharide serotype 14 using a modification of phenol-sulfuric acid method. $J$. Microbiol. Methods, 52: 69-73.

Girmay, Z.; Gorems, W.; Birhanu, G. and Zewdie, S. (2016): Growth and yield performance of Pleurotus ostreatus (Jacq. Fr.) Kumm (oyster mushroom) on different substrates. AMB Expr, 6(87): 1-7.

Hao, C.; Yang, J.; Liang, T.; Zhang, J. and Sun, R. (2017): Structural elucidation and morphological observation of a polysaccharide from Pleurotus eryngii obtained by alkaline extraction. J. Carbohydr. Chem., 36 (3): 129-140.

Jahan, A. and Singh, B.K. (2019): Mushroom value chain and role of value addition. I.J.B.R., 9(1): 5-14.

Jeena; Gajendra.; Punatha; Om Prakash; Mahesh Chandra, and Kushwaha (2016): "Study on in vitro antioxidant potential of some cultivated Pleurotus species (Oyster mushroom)." Indian Journal of Natural Products and Resources (IJNPR) [Formerly Natural Product Radiance (NPR)], 5(1): 56-61.

Khani M.; Bahrami A.; Ghafari M. D. (2015): Optimization of operating parameters for anti-corrosive biopolymer production by Chryseobacterium Indologenes MUT2 using central composite design methodology. J Taiwan Inst. Chem. Eng., 59:165-172.

Khuri A. I., Mukhopadhyay S. (2010): Response surface methodology. WIREs Comp Stat., 2(2):128-149.

Kogana, G.; Matulova, M. and Michalkova, E. (2002): Extracellular Polysaccharides of Penicillium vermiculatum. $\mathrm{Z}$. Naturforsch., 57 (7): 452-458.

Latha, K. and baskar, R. (2014): Comparative study on the production, purification and characterization of exopolysaccharides from oyster mushrooms, pleurotus florida and hypsizygus ulmarius and their applications. Proceedings of the 8th international conference on mushroom biology and mushroom products (ICMBMP8).

Lee, K.H. and Yoon, W.H. (2009): Production of exopolysaccharide from submerged culture of Grifola frondosa and its antioxidant activity. Food Sci. Biotechnol., 18(5): 1253-1257.

Li, N.; Li, L.; Fang, J.C.; Wong, J.H.;Ng,T.B.; Jiang, Y. ; Wang, C.R. ; Zhang, N.Y. ; Wen, T.Y. ; Qu, L.Y. ; Lv, P.Y. ; Zhao, R. ; Shi, B. ; Wang,Y.P. ; Wang, X.Y. and Liu, F. (2012): Isolation and identification of a novel polysaccharide-peptide complex with antioxidant, anti-proliferative and hypoglycaemic activities from the abalone mushroom. Biosci. Rep., 32(3): 221-228. 
Liu, L.; Lu, Y.; Li, X.; Zhou, L.; Yang, D.; Wang, L., et al. (2015): A novel process for isolation and purification of the bioactive polysaccharideTLH-3' from Tricholomalo- bayense. Process Biochemistry, 50: 1146-1151.

Monali Bhakta; Prasant Kumar (2013): Mushroom Polysaccharides as a Potential Prebiotics. International Journal of Health Sciences \& Research. 3(8): 77-84.

Nour EL-Dein, M.M.; Elfallal, A.A.; Toson, E.A. and Herecher, F.E. (2004): Exopolysaccharides production by Pleurotus pulmonarius. Pkistan J. Biol. Sci., 7(6): 1078-1084.

Plackett R. L.; Burman J. P. (1946): The design of optimum multi factorial experiments .Biometrika., 33(4):305325.

Rahar, S.; Swami,G.; Nagpal, N.; Nagpal, M.A. and Singh,G.S. (2011): Preparation, characterization, and biological properties of $\beta$-glucans. J. Adv. Pharm. Tech. Res., 2 (2): 94-103.

Shen, J.W.; Shi, C.W. and Xu, C.P. (2013): Exopolysaccharides from Pleurotus pulmonarius Fermentation Optimization, Characterization and Antioxidant Activity. Food Technol. Biotechnol., 51(4): 520-527.
Mushrooms: Improving Human Health and Promoting Quality Life. Int. J. Microbiol. Res., Article ID 376387, 2015(7): 1-14.

Wu, Y.C.; Liang, Z.C.; Lu, C.P.; Wu, S.H. (200 8): Effect of carbon and nitrogen sources on the production and carbohydrate composition of exopolysaccharide by submerged culture of Pleurotus citrinopileatus. J. Food Drug Anal., 16(2): 61-67.

Xu, C. P.; Kim, S. W.; Hwang, H. J. and Yun, J. W. (2006): Production of exopolysaccharides by submerged culture of an enthomopathogenic fungus, Paecilomyces tenuipes C240 in stirred tank and air lift reactor. Bioresour. Technol., 97(5): 770-777.

Zhao, X.; Sun, H.; Hou, A.; Zhao, Q.; Wei, T. and Xin, W. (2005): Ant ioxidant properties of two gallotannins isolated from the leaves of Pistacia weinmannifolia. Biochim. Biophys. Acta., 1725(1): 103-110.

Valverde, M.E.; Hernandez-Perez,T. and Paredes-Lopez, O. (2018): Edible

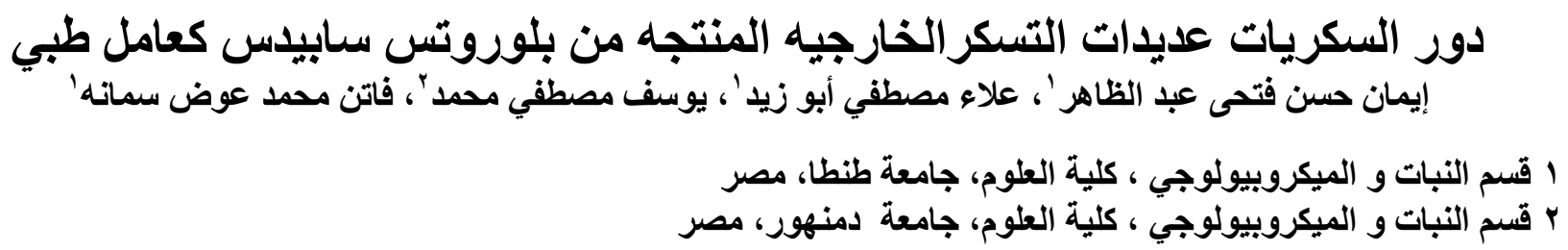

أظهرت الدر اسة ان زر اعة فطر البلوروتس سابيدس على وسط غذائى بحتوى على النشا و الجلوكوز لمدة ( ( ) يوم كفترة تحضبن عند درجة (r و Y ) درجة سليلوزية أعطت أعلي إنتاجية من السكريات عديدات التسكر المستخرجة خارجيا. وأوضحت النتائج بعد التحليل باستخدام جهاز HPLC أن عديدات التسكر الخارجيه المستخلصة من فطر البلوروتس سابيدس يتكون من السكريات بيتا-

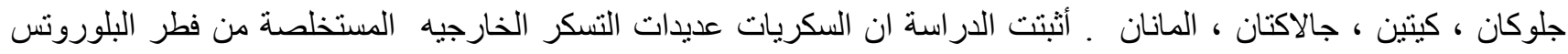

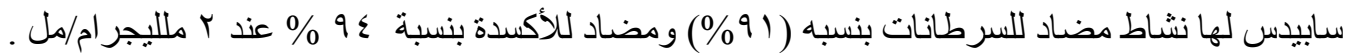

